\title{
Neurosteroid Levels in Patients with Obsessive-Compulsive Disorder
}

\author{
Lale Gonenir Erbay ${ }^{1 凶}$ and Sukru Kartalci \\ ${ }^{1}$ Department of Psychiatry, State Hospital of Malatya, Malatya, Turkey \\ ${ }^{2}$ Department of Psychiatry, Faculty of Medicine, Inonu University, Malatya, Turkey
}

\begin{abstract}
Objective Changes in serum neurosteroid levels have been reported in stress-related disorders such as anxiety and depression, but not in patients with obsessive-compulsive disorder (OCD). We thus investigated such changes in patients with OCD.

Methods We compared the serum levels of progesterone, pregnanolone, dehydroepiandrosterone (DHEA), dehydroepiandrosterone sulphate (DHEA-S), cortisol and testosterone in 30 patients with OCD and 30 healthy controls.

Results When male and female patients were evaluated together, DHEA and cortisol levels were significantly higher in patients with OCD than the control group. When the genders were evaluated separately, DHEA and cortisol levels were higher in female patients than the female controls. The increase in DHEA levels in female patients is likely an effect of the hypothalamic-pituitary-adrenal (HPA) axis. In contrast, cortisol levels in male patients were higher than the control group, while testosterone levels were lower. The increased cortisol and decreased testosterone levels in male patients likely involves the hypothalamic-pituitary-gonadal (HPG) axis.

Conclusion These findings suggest that neurosteroid levels in patients with OCD should be investigated together with the HPA and HPG axes in future studies.

Psychiatry Investig 2015;12(4):538-544
\end{abstract}

Key Words Obsessive-compulsive disorder, Neurosteroid, Gender.

\section{INTRODUCTION}

Obsessive-compulsive disorder (OCD), a chronic psychiatric disorder characterised by unwanted repetitive thoughts and compulsive behaviours, is directly related to stress with the symptoms increasing under stressful conditions. ${ }^{1}$ The cerebrospinal fluid (CSF) corticotropin-releasing hormone (CRH) levels and the hypothalamic-pituitary-adrenal (HPA) axis activity have been shown to increase in patients with OCD. ${ }^{2}$ The lack of cortisol suppression on the dexamethasone suppression test (DST) is an indication of HPA axis abnormality in these patients, ${ }^{3,4}$ which may be explained by a possible insensitivity of the pituitary gland due to high CRH levels. ${ }^{5}$ Additionally, patients with OCD have been shown to have differing levels of melatonin, ${ }^{6}$ corticotropin, arginine vasopressin, ${ }^{2}$ glutamate ${ }^{7}$ and oxytocin. ${ }^{8}$

Received: February 12, 2014 Revised: January 26, 2015

Accepted: February 24, 2015 Available online: September 30, 2015

$\triangle$ Correspondence: Lale Gonenir Erbay, MD

Department of Psychiatry, Malatya State Hospital, 44100 Malatya, Turkey

Tel: +90 42221210 10, Fax: +904223410787

E-mail: lalegonenir@hotmail.com

(a) This is an Open Access article distributed under the terms of the Creative Commons Attribution Non-Commercial License (http://creativecommons.org/licenses/by$\mathrm{nc} / 3.0$ ) which permits unrestricted non-commercial use, distribution, and reproduction in any medium, provided the original work is properly cited.
Neurosteroids are a group of steroid hormones that have direct effects on the brain. In addition to being synthesised in the brain itself, neurosteroids are also secreted by the adrenal cortex and gonads, which are parts of the HPA axis. ${ }^{9-11}$ Of these neurosteroids, dehydroepiandrosterone sulphate (DHEA-S), and to a lesser extent dehydroepiandrosterone (DHEA), are potent noncompetitive antagonists ${ }^{12,13}$ of the gamma-amino butyric acid-A (GABA-A) receptors in the brain and have been shown to regulate compulsive behaviour and anxiogenic activity when injected into rodents. ${ }^{13-15}$ Although progesterone, another neurosteroid, is anxiogenic, its metabolites (pregnanolone and allopregnanolone) show anxiolytic and hypnotic properties due to their GABA-A agonistic effects. ${ }^{16}$ Testosterone is both a male sex hormone and a neurosteroid that has been reported to play a causal role in psychiatric diseases. ${ }^{17-22}$ Studies have reported changes in neurosteroid levels in pervasive anxiety disorders, posttraumatic stress disorder (PTSD), phobias, panic disorder and depression. ${ }^{23-29}$ However, no previous studies have investigated neurosteroid levels in patients with stressrelated OCD and anxiety disorder.

Based on these findings, the aim of this study was to investigate neurosteroid levels in the anxiety disorder OCD. Taking into account the increase in levels of neurosteroids, such as DHEA and DHEA-S in anxiety disorders in previous studies, 
in this study, we expected to find increased neurosteroid levels in patients with OCD. Evaluating these data is important as it can help in understanding the neurobiology of OCD, especially considering the current lack of adequate data in the literature.

\section{METHODS}

This study evaluated 30 patients with OCD between the ages of 18 and 49 years who presented at the İnönü University Faculty of Medicine Psychiatry Outpatients Department, along with 30 healthy volunteers as the control group. OCD diagnosis was made by a psychiatry resident and a psychiatrist following an interview using the Structured Clinical Interview for DSM-IV-TR/Clinical Version (SCID-1/CV). Major systemic disease, endocrine pathology, neurological disease, head trauma, alcohol/substance addiction, electroconvulsive therapy (ECT), additional psychiatric disorders other than OCD in the past or during the interview, mental retardation, pregnancy or breast-feeding and using oral contraceptives were exclusion criteria for the patient group. The patients were not receiving psychiatric medical treatment during the study. For females, blood samples were collected during the midluteal phase of the menstrual period.

The control group consisted of 30 age- and sex-matched healthy volunteers who had no previous or current psychiatric, neurological, systemic, or endocrine disease, drug use, or drug/alcohol addiction and who were not pregnant or nursing.

Disease severity was evaluated with the Yale-Brown Obsessive Compulsive scale.

Blood samples were taken between 09:00 and 10:00 in the morning, after $12 \mathrm{~h}$ of fasting and a 30 -min rest. The samples were then centrifuged at $4,000 \mathrm{rpm}$ and stored at $-70^{\circ} \mathrm{C}$.

The study protocol was approved by the İnönü University Medical Faculty Ethics Committee. The study was conducted in accordance with the principles of the "Helsinki Human Rights Agreement-2001 version" and "Good Clinical Practice." Written consent was obtained from the participants.

\section{Biochemical method}

The blood samples were analysed at the İnönü University Faculty of Medicine's Department of Biochemistry laboratories. Progesterone, total testosterone, cortisol and DHEA-S were studied with a Siemens kit and an Immulite 2000 hormone analyser (Siemens Healthcare Diagnostics Products Ltd., Brighton, UK). Chemiluminescence was used as the immunoassay method. For DHEA-S, the conversion factor was $\mu \mathrm{g} / \mathrm{dL} \times 0.02714 \rightarrow$ $\mu \mathrm{mol} / \mathrm{L}$, calibration range $15-1.000 \mu \mathrm{g} / \mathrm{dL}(0.41-27 \mu \mathrm{mol} / \mathrm{L})$ and analytical sensitivity $3 \mu \mathrm{g} / \mathrm{dL}(0.08 \mu \mathrm{mol} / \mathrm{L})$; for progesterone, the conversion factor was $\mathrm{ng} / \mathrm{mL} \times 3.18 \rightarrow \mathrm{nmol} / \mathrm{L}$, calibra- tion range $0.2-40 \mathrm{ng} / \mathrm{mL}(0.6-127 \mathrm{nmol} / \mathrm{L})$ and analytical sensitivity $0.1 \mathrm{ng} / \mathrm{mL}(0.3 \mathrm{nmol} / \mathrm{L})$; for cortisol, the conversion factor was $\mu \mathrm{g} / \mathrm{dL} \times 27.59 \rightarrow \mu \mathrm{mol} / \mathrm{L}$, calibration range $1-50 \mu \mathrm{g} / \mathrm{dL}\left(28^{-}\right.$ $1.380 \mu \mathrm{mol} / \mathrm{L})$ and analytical sensitivity $0.20 \mu \mathrm{g} / \mathrm{dL}(5,5 \mu \mathrm{mol} /$ $\mathrm{L})$; for testosterone, the conversion factor was $\mathrm{ng} / \mathrm{mL} \times 0.03467 \rightarrow$ $\mathrm{nmol} / \mathrm{L}$, calibration range $20-1.600 \mathrm{ng} / \mathrm{mL}(0.7-55 \mathrm{nmol} / \mathrm{L})$ and analytical sensitivity $15 \mathrm{ng} / \mathrm{mL}(0.5 \mathrm{nmol} / \mathrm{L})$. Pregnanolone and DHEA were studied with a DRG kit (DRG Instruments $\mathrm{GmbH}$, Marburg, Germany) and the Elisa method (Siemens Healthcare Diagnostics Products Ltd.).

\section{Statistical method}

The Shapiro-Wilk test was used to determine whether the distribution of the variables was normal. The demographic characteristics of the patient and control groups were compared with the independent samples t-test. The Yates corrected chi-square test was used to compare the groups by gender. The independent samples t-test was used to analyse neurosteroid levels in the patient and control groups without taking gender into account. The patients were then evaluated with the Pearson correlation coefficient to see the effect of disease duration and age. The independent samples t-test was used to evaluate within group neurosteroid levels for females and males. We compared four groups of subjects: female patients, healthy females, male patients and healthy males. For between-group differences, levels of DHEA-S showed a normal distribution and were evaluated with a one-way analysis of variance; the distributions of the other neurosteroids (DHEA, testosterone, progesterone, cortisol and pregnanolone) were not normal and were evaluated with the Kruskal-Wallis $\mathrm{H}$ test. When the univariate analysis was significant, multiple comparisons were performed with the Tukey test because the variances were homogeneous. The relationships between OCD severity and levels of DHEA, pregnanolone, progesterone and testosterone did not show a normal distribution and were examined with the Spearman correlation analysis. In contrast, the relationships between OCD severity and levels of DHEA-S and cortisol showed a normal distribution and were examined with Pearson's correlation coefficient.

\section{RESULTS}

\section{The sociodemographic characteristics of the groups}

No significant differences were observed between the patient and control groups for sociodemographic characteristics (Table 1). The mean age of females in the patient group (34.60 \pm 11.37 years, $\mathrm{n}=20)$ and control group $(34.05 \pm 9.87$ years, $\mathrm{n}=20)$ did not differ ( $\operatorname{sig}=0.871$ ). For males, the mean age in the pa-

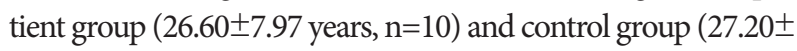
6.66 years, $\mathrm{n}=10$ ) also did not differ ( $\operatorname{sig}=0.622$ ). 
Table 1. Comparison of patient and control groups in terms of sociodemographic characteristics

\begin{tabular}{lccc}
\hline \multicolumn{1}{c}{ Demographic data } & $\begin{array}{c}\text { Patient group } \\
\text { N=30, Mean } \pm \text { SD }\end{array}$ & $\begin{array}{c}\text { Control group } \\
\text { N=30, Mean } \pm \text { SD }\end{array}$ & Comparison \\
\hline Age & $31.93 \pm 10.92$ & $31.77 \pm 9.40$ & t: $0.16, p: 0.871$ \\
Sex $(\mathrm{M} / \mathrm{F})$ & $10 / 20$ & $10 / 20$ & $\chi^{2}: 0.00, \mathrm{p}: 0.608$ \\
Smoking/non smoking & $5 / 25$ & $10 / 20$ & $\chi^{2}: 2.22, \mathrm{p}: 0.233$ \\
Disease duration (year) & $7.87 \pm 6.658$ & & \\
\hline
\end{tabular}

$\mathrm{N}$ : number of subjects

Table 2. Comparison of groups in terms of neurosteroid levels

\begin{tabular}{lccc}
\hline & $\begin{array}{c}\text { Patient group } \\
\text { N=30, Mean } \pm \text { SD }\end{array}$ & $\begin{array}{c}\text { Control group } \\
\text { N=30, Mean } \pm \text { SD }\end{array}$ & Comparison \\
\hline DHEA & $14.75 \pm 7.77$ & $9.73 \pm 5.28$ & $\mathrm{t}: 2,925 \mathrm{p}: 0.005$ \\
DHEA-S & $190.54 \pm 99.04$ & $170.49 \pm 99.18$ & $\mathrm{t}: 0,784 \mathrm{p}: 0.436$ \\
Pregnanolone & $6.04 \pm 2.87$ & $5.45 \pm 2.53$ & $\mathrm{t}: 0,834 \mathrm{p}: 0.408$ \\
Progesterone & $2.51 \pm 3.57$ & $4.03 \pm 5.26$ & $\mathrm{t}:-1,316 \mathrm{p}: 0.194$ \\
Cortisol & $15.05 \pm 5.47$ & $9.54 \pm 3.43$ & $\mathrm{t}: 4,661 \mathrm{p}<0.001$ \\
Testosterone & $154.56 \pm 181.61$ & $175.37 \pm 225.96$ & $\mathrm{t}:-0.393 \mathrm{p}: 0.696$ \\
\hline
\end{tabular}

$\mathrm{N}$ : number of subjects, DHEA: dehydroepiandrosterone, DHEA-S: dehydroepiandrosterone sulphate

\section{The comparison of neurosteroid values between the groups}

DHEA and cortisol levels were significantly higher in patients than in controls. No differences were observed for DHEAS, pregnanolone, progesterone and testosterone levels (Table 2). The groups were divided according to gender to account for the possible influence of gender on neurosteroid levels. In females, DHEA and cortisol levels were significantly higher in the patients relative to controls. Levels of DHEA-S, pregnanolone, progesterone and testosterone showed no difference between the female patients and control group. Cortisol levels in male patients were significantly higher than the male control group, while testosterone levels were significantly lower. No differences in DHEA, DHEA-S, pregnanolone and progesterone levels were observed between the male patient and control groups (Table 3).

\section{Correlation evaluation in the patient group}

A positive correlation was present between DHEA and cortisol levels in the patient group ( $\mathrm{p}=0.007)$. Severity of the disease was evaluated with the Yale-Brown obsessive-compulsive scale (Y-BOCS). The mean compulsion score of the patient group was $14.10 \pm 2.46$, the mean obsession score was $14.53 \pm 2.31$ and the total mean score was $28.30 \pm 5.09$. In the patient group, no statistically significant relationship was found between the severity of the disease (Y-BOCS scores) and neurosteroid levels (DHEA: sig=0.535, DHEA-S: sig $=0.136$, pregnanolone: $\operatorname{sig}=$ 0.406 , progesterone: $\operatorname{sig}=0.996$, cortisol: $\mathrm{sig}=0.862$, testosterone: sig $=0.059$ ).

No relationship was detected between the disease duration and age and the neurosteroid levels.

When stratified by gender, a positive significant relationship was present between DHEA and cortisol levels and compulsion (Y-BOCS) scores in male patients ( $\mathrm{p}=0.017, \mathrm{p}=0.019$, respectively); no significant relationship was found in female patients, which suggests that the compulsion scores increased in relation to the DHEA and cortisol levels in male patients.

\section{DISCUSSION}

To date, neurosteroid levels in subjects with OCD have been evaluated in one animal study and one case study. ${ }^{14,30}$ In the case study, DHEA and DHEA-S levels were investigated in a single patient. Our study is the first to investigate neurosteroid levels in a sample group of patients with OCD.

One of our main findings was a higher level of DHEA and cortisol in patients with OCD than the control group. This finding verifies that in a group of 30 patients, the results of the $\mathrm{Bi}$ gos et al. ${ }^{30}$ study concurred in only one patient with OCD.

In previous studies, serum DHEA and cortisol levels have been found to be higher in patients with anxiety disorders such as panic disorder, ${ }^{24}$ PTSD, ${ }^{26,31,32}$ depression ${ }^{28,33}$ and eating disorders. ${ }^{34}$ Data have shown that the plasma concentrations of progesterone and DHEA were significantly higher in male patients with PD than in controls. ${ }^{24}$ Spivak et al. ${ }^{26}$ demonstrated that patients with PTSD had significantly higher levels of plasma DHEA and DHEA-S relative to controls. Although no relationship has been found between the severity of depression and serum DHEA levels in patients with major depression who did not use medication, a positive correlation was reported be- 
Table 3. The comparison of female/male patients and controls in terms of neurosteroid values

\begin{tabular}{|c|c|c|c|c|}
\hline Dependent variable & Groups (A) & Groups (B) & Mean difference (A-B) & $\mathrm{p}$ value \\
\hline \multirow[t]{6}{*}{ DHEA } & 1 & 2 & -0.22250 & 1.00 \\
\hline & & 3 & 6.75650 & 0.009 \\
\hline & & 4 & 1.32250 & 0.953 \\
\hline & 2 & 3 & 6.97900 & 0.037 \\
\hline & & 4 & 1.54500 & 0.951 \\
\hline & 3 & 4 & -5.43400 & 0.147 \\
\hline \multirow[t]{6}{*}{ DHEA-S } & 1 & 2 & -72.83000 & 0.179 \\
\hline & & 3 & 29.33500 & 0.741 \\
\hline & & 4 & -71.33000 & 0.194 \\
\hline & 2 & 3 & 102.16500 & 0.027 \\
\hline & & 4 & 1.50000 & 1.000 \\
\hline & 3 & 4 & -100.66500 & 0.030 \\
\hline \multirow[t]{6}{*}{ Cortizol } & 1 & 2 & -3.20250 & 0.268 \\
\hline & & 3 & 4.75950 & 0.008 \\
\hline & & 4 & 3.78650 & 0.145 \\
\hline & 2 & 3 & 7.96200 & $<0.001$ \\
\hline & & 4 & 6.98900 & 0.005 \\
\hline & 3 & 4 & -0.97300 & 0.944 \\
\hline \multirow[t]{6}{*}{ Pregnanolone } & 1 & 2 & 0.51550 & 0.957 \\
\hline & & 3 & 1.56950 & 0.243 \\
\hline & & 4 & -0.87050 & 0.827 \\
\hline & 2 & 3 & 1.05400 & 0.729 \\
\hline & & 4 & -1.38600 & 0.641 \\
\hline & 3 & 4 & -2.44000 & 0.089 \\
\hline \multirow[t]{6}{*}{ Progesterone } & 1 & 2 & 2.657650 & 0.388 \\
\hline & & 3 & -1.887000 & 0.511 \\
\hline & & 4 & 1.847450 & 0.685 \\
\hline & 2 & 3 & -4.544650 & 0.041 \\
\hline & & 4 & -0.810200 & 0.975 \\
\hline & 3 & 4 & 3.734450 & 0.124 \\
\hline \multirow[t]{6}{*}{ Testosterone } & 1 & 2 & -344.75500 & $<0.001$ \\
\hline & & 3 & 13.38500 & 0.941 \\
\hline & & 4 & -433.95500 & $<0.001$ \\
\hline & 2 & 3 & 358.14000 & $<0.001$ \\
\hline & & 4 & -89.20000 & 0.047 \\
\hline & 3 & 4 & -447.34000 & $<0.001$ \\
\hline
\end{tabular}

The mean difference is significant at the 0.05 level. 1: female patients, 2: male patients, 3: female controls, 4: male controls. DHEA: dehydroepiandrosterone, DHEA-S: dehydroepiandrosterone sulphate

tween the degree of anxiety and serum DHEA levels. ${ }^{35}$ The elevated DHEA levels found in the present study also support the relationship between DHEA and high levels of anxiety in patients with OCD. ${ }^{36}$

ACTH regulates cortisol and DHEA secretion from the adrenal gland. Cortisol, a stress hormone, has previously been shown to be higher in patients with OCD due to adrenal gland function. ${ }^{6,37,38}$ The elevated DHEA and cortisol levels in the patients with OCD in our study suggest that the increased DHEA originates from the adrenal gland.

Whether the increase in DHEA levels in patients is the cause or result of anxiety is not fully understood. DHEA is 
believed to have an antiglucocorticoid effect, ${ }^{39,40}$ and levels are thought to increase to reduce the destructive effect of cortisol $^{41}$ produced under stressful conditions. The increase in DHEA can therefore be interpreted as a compensatory mechanism developed to reduce anxiogenic activity. Therefore, the DHEA increase can be seen as a result of anxiety rather than a cause.

Additionally, serum DHEA levels are a reflection of the levels in the brain. ${ }^{42,43}$ DHEA in the brain has a two-way effect on GABA-A receptors. ${ }^{12,13}$ It causes positive allosteric modulation at low doses and negative allosteric modulation at high doses. Rats with low DHEA levels were reported to experience lower anxiety compared to the control group. ${ }^{44}$ Thus, the increase in serum concentration of DHEA, which is a GABA receptor antagonist, may be considered to have a causal role in the pathophysiology of anxiety. GABA receptors as well as NMDA receptors have been reported to act as mediators for the causal role of DHEA on anxiety. ${ }^{45}$ DHEA has been shown to block the anxiolytic effects of the NMDA receptor antagonist dizocilpine ${ }^{46}$ and to be a positive modulator of the NMDA receptor. ${ }^{47}$ The effects of these neurosteroids on the GABA and glutamate systems may affect the dopamine and serotonin systems and therefore influence OCD pathophysiology. ${ }^{14}$

Neurosteroids are secreted by the brain and adrenal cortex and are also secreted by sexual organs such as the ovaries and testes, ${ }^{9}$ which suggests the need to evaluate the neurosteroid levels separately for males and females. The DHEA and cortisol levels were significantly higher in female patients with OCD than the female control group. In males, however, cortisol levels were significantly higher in patients with OCD, but the levels of DHEA showed no difference. Although the reason for the increase in DHEA levels in females with OCD is unclear, a possible explanation may be the different physiological effects of androgenic neurosteroids between genders. ${ }^{48}$ The sample size of male patients may also be a cause of this finding.

Progesterone is a primary progestin produced by ovarian corpus luteum. Although it is anxiogenic itself, its metabolites (allopregnanolone and pregnanolone) show anxiolytic and hypnotic properties due to their GABA-A agonistic effects. ${ }^{16}$ It is known to play an important role in the development of premenstrual syndrome symptoms, ${ }^{49}$ and low levels of pregnanelone have been reported in pervasive anxiety disorder and social phobia. $^{25,27}$ The serum levels of pregnanolone and progesterone are also expected to be different in people with OCD. However, we found no significant difference regarding pregnanolone and progesterone levels between the patient and control groups in our study.

Another important finding of our study was the nonsignificant increase in testosterone levels in female patients and a significant decrease in male patients. The effects of testosterone, also a neurosteroid, on human behaviour have been known for many years. Studies investigating testosterone levels in psychiatric disorders have reported contradictory results. ${ }^{18-20,22,48}$ The main source of testosterone is the testicles in males and the ovaries in females. A small amount of testosterone is secreted by the adrenal gland in both sexes. The increase in DHEA and cortisol, which are neurosteroids originating in the adrenal gland, accompanied by the increase in testosterone found in female patients with OCD, suggests that the source of the elevated testosterone is the adrenal gland. HPA axis hyperactivity has been reported to cause a decrease in the activity of the hypothalamic-pituitary-gonadal axis (HPG) during depression. Since $90 \%$ of testosterone in men is produced by the testicles, a decrease in production may occur in the testicles of males with OCD despite an increase from the adrenal gland. This would be similar to the case of depression, ${ }^{50}$ in which testosterone from the testicles decreases due to the suppression of the HPG axis.

The lack of correlation between the neurosteroid levels and the Yale-Brown Obsessive-Compulsive Scale scores in this study undermines any relationship. However, a positive correlation between compulsion scores and DHEA and cortisol levels has been shown in male patients.

Although the results of this initial study indicate a partial role of neurosteroids in OCD, this relationship has not been fully elucidated. One of the main reasons for this was the low number of patients. Two constraints of this study were that multiple measurements were not performed that would reflect diurnal variations, and seasonal variations were not taken into account. Studies evaluating males and females separately and with a larger subject pool are required to clarify some aspects of the relationship between neurosteroids and OCD.

In conclusion, this study shows an increase in DHEA levels, probably from the HPA axis, in parallel with cortisol levels in people with OCD, especially females. Testosterone levels have been shown to decrease in males with OCD, possibly due to the HPG axis. Considering the effects of neurosteroids in the brain, investigating these findings is important to clarify the pathophysiology of anxiety disorder and OCD. In future studies, the investigation of neurosteroid levels in patients having OCD together with the HPA and HPG axes will shed light on the subject.

\section{REFERENCES}

1. Findley DB, Leckman JF, Katsovich L, Lin H, Zhang H, Grantz H, et al. Development of the Yale Children's Global Stress Index (YCGSI) and its application in children and adolescents ith Tourette's syndrome and obsessive-compulsive disorder. J Am Acad Child Adolesc Psychiatry 2003; 42:450-457.

2. Altemus M, Pigott T, Kalogeras KT, Demitrack M, Dubbert B, Murphy $\mathrm{DL}$, et al. Abnormalities in the regulation of vasopressin and corticotropin releasing factor secretion in obsessive-compulsive disorder. Arch Gen Psychiatry 1992;49:9-20. 
3. Catapano F, Monteleone P, Maj M, Kemali D. Dexamethasone suppression test in patients with primary obsessive-compulsive disorder and in healthy controls. Neuropsychobiology 1990;23:53-56.

4. Cottraux JA, Bouvard M, Claustrat B, Juenet C. Abnormal dexamethasone suppression test in primary obsessive-compulsive patients: a confirmatory report. Psychiatry Res 1984;13:157-165.

5. Bailly D, Servant D, Dewailly D, Beuscart R, Racadot A, Fossati P. Corticotropin releasing factor stimulation test in obsessive compulsive disorder. Biol Psychiatry 1994;35:143-146.

6. Catapano F, Monteleone P, Fuschino A, Maj M, Kemali D. Melatonin and cortisol secretion in patients with primary obsessive-compulsive disorder. Psychiatry Res 1992;44:217-225.

7. Chakrabarty K, Bhattacharyya S, Christopher R, Khanna S. Glutamatergic dysfunction in OCD. Neuropsychopharmacology 2005;30:17351740.

8. Leckman JF, Goodman WK, North WG, Chappell PB, Price LH, Pauls DL, et al. Elevated cerebrospinal fluid levels of oxytocin in obsessivecompulsive disorder. Comparison with Tourette's syndrome and healthy controls. Arch Gen Psychiatry 1994;51:782-792.

9. Pluchino N, Santoro A, Casarosa E, Wenger JM, Genazzani AD, Petignat $\mathrm{P}$, et al. Advances in neurosteroids: role in clinical practice. Climacteric 2013;16(Suppl 1):8-17.

10. Zinder O, Dar DE. Neuroactive steroids: their mechanism of action and their function in the stress response. Acta Physiol Scand 1999;167: 181-188.

11. Kartalcı Ş, Eşel E. Neurosteroids: psychopharmacological and behavioral effects. Bull Clin Psychopharmacol 2004;14:38-49.

12. Majewska MD. Neurosteroids: Endogenous bimodal modulators of the GABAA receptor. Mechanism of action and physiological significance. Prog Neurobiol 1992;38:379-395.

13. Majewska MD, Demirgören S, Spivak CE, London ED. The neurosteroid dehydroepiandrosterone sulfate is an allosteric antagonist of the GABAA receptor. Brain Res 1990;526:143-146.

14. Umathe SN, Vaghasiya JM, Jain NS, Dixit PV. Neurosteroids modulate compulsive and persistent behavior in rodents: implications for obsessive-compulsive disorder. Prog Neuropsychopharmacol Biol Psychiatry 2009;33:1161-1166.

15. Le Mellédo J-M, Baker GB. Role of progesterone and other neuroactive steroids in anxiety disorders. Expert Rev Neurother 2004;4:851-860.

16. Bitran D, Dugan M, Renda P, Ellis R, Foley M. Anxiolytic effects of the neuroactive steroid pregnanolone (3 alpha-OH- 5 beta-pregnan-20-one) after microinjection in the dorsal hippocampus and lateral septum. Brain Res 1999;850:217-224.

17. Sundblad C, Bergman L, Erikson E. High levels of free testosterone in women with bulimia nervosa. Acta Physiol Scand 1994;90:397-398.

18. Seidman SN. Testosterone deficiencyand mood in aging men: pathogenic and therapeutic interactions. World J Biol Psychiatry 2003;4:1420.

19. Markianos M, Tripodianakis J, Sarantidis D, Hatzimanolis J. Plasma testosterone and dehydroepiandrosterone sulfate in male and female patients with dysthymic disorder. J Affect Disorder 2007;101:255-258.

20. Davies SR, Tran J. Testosterone influences libido and well being in women. Trends Endocrinol Metabol 2001;12:33-37.

21. Giltay EJ, Enter D, Zitman FG, Penninx BW, van Pelt J, Spinhoven P, et al. Salivary testosterone: Associations with depression, anxiety disorders, and antidepressant use in a large cohort study. J Psychosom Res 2012;72: 205-213.

22. Sachar EJ, Halpern F, Rosenfeld RS, Galligher TF, Hellman L. Plasma and urinary testosterone levels in depressed men. Arch Gen Psychiatry 1973;28:15-18.

23. Brambilla F, Biggio G, Pisu MG, Bellodi L, Perna G, Bogdanovich-Djukic V, et al. Neurosteroid secretion in panic disorder. Psychiatry Res 2003; 118:107-116.

24. Brambilla F, Mellado C, Alciati A, Pisu MG, Purdy RH, Zanone S, et al. Plasma concentrations of anxiolytic neuroactive steroids in men with panic disorder. Psychiatry Res 2005;135:185-190.

25. Semeniuk T, Jhangri GS, Le Melledo JM. Neuroactive steroid levels in patients with generalized anxiety disorder. J Neuropsychiatry Clin Neurosci 2001;13:396-398.

26. Spivak B, Maayan R, Kotler M, Mester R, Gil-Ad I, Shtaif B, et al. Elevated circulatory level of GABA(A)-antagonistic neurosteroids in patients with combat-related post-traumatic stres disorder. Psychol Med 2000; 30:1227-1231.

27. Heydari B, Le Melledo JM. Low pregnenolone sulphate plasma concentrations in patients with generalized social phobia. Psychol Med 2002; 32:929-933.

28. Kartalcı Ş, Eşel E, Özsoy S, Kula M, Turan T. Neurosteroids and cognitive functions in depressed women. Bull Clin Psychopharmacol 2008; 18:9-21.

29. Hauser I, Deuschle M, Luppa P, Schweiger U, Standhardt H, Weber B. Increased diurnal plasma concentrations of dehydroepiandrostenodion in depressed patients. J Clin Endocrinol Metab 1998;83:3130-3133.

30. Bigos KL, Folan MM, Jones MR, Haas GL, Kroboth FJ, Kroboth PD. Dysregulation of neurosteroids in obsessive compulsive disorder. J Psychiatr Res 2009;43:442-445.

31. Kellner M, Muhtz C, Peter F, Dunker S, Wiedemann K, Yassouridis A. Increased DHEA and DHEA-S plasma levels in patients with post-traumatic stress disorder and a history of childhood abuse. J Psychiatr Res 2010;44:215-219.

32. Gill J, Vythilingam M, Page GG. Low cortisol, high DHEA, and high levels of stimulated TNF-alpha, and IL-6 in women with PTSD. J Trauma Stress 2008;21:530-539.

33. Michikawa T, Nishiwaki Y, Nakano M, Iwasawa S, Yamada M, Asakura $\mathrm{K}$, et al. Higher serum dehydroepiandrosterone sulfate levels are protectively associated with depressive symptoms in men, but not in women: a community-based cohort study of older Japanese. Am J Geriatr Psychiatry 2013;21:1154-1163.

34. Monteleone P, Luisi M, Colurgio B, Casarosa E, Ioime R, Genazzani AR, et al. Plasma levels of neuroactive steroids are increased in untreated women with anorexia nervosa or bulimia nervosa. Psychosom Med 2001;63:62-68.

35. Hsiao CC. Positive correlation between anxiety severity and plasma levels of dehydroepiandrosterone sulfate in medication-free patients experiencing a majör episode of depression. Psychiatry Clin Neurosci 2006;60:746-750.

36. Sullivan GM, Coplan JD, Kent JM, Gorman JM. The noradrenergic system in pathological anxiety: a focus on panic with relevance to generalized anxiety and phobias. Biol Psychiatry 1999;46:1205-1218.

37. Kluge M, Schüssler P, Künzel HE, Dresler M, Yassouridis A, Steiger A. Increased nocturnal secretion of ACTH and cortisol in obsessive compulsive disorder. J Psychiatr Res 2007;41:928-933.

38. Gustafsson PE, Gustafsson PA, Ivarsson T, Nelson N. Diurnal cortisol levels and cortisol response in youths with obsessive-compulsive disorder. Neuropsychobiology 2008;57:14-21.

39. Maninger N, Wolkowitz OM, Reus VI, Epel ES, Mellon SH. Neurobiological and neuropsychiatric effects of dehydroepiandrosterone (DHEA) and DHEA-sülfate (DHEA-S). Front Neuroendocrinol 2009;30:65-91.

40. Wolkowitz OM, Reus VI. Treatment of depression with antiglucocorticoid drugs. Psychosom Med 1999;61:698-711.

41. Boudarene M, Legros JJ, Timsit-Berthier M. Study of the stress response: role of anxiety, cortisol and DHEAs. Encephale 2002;28:139-146.

42. Bernardi F, Casarosa E, Pluchino N, Palumbo M, Genazzani AD, Luisi S, et al. Effect of dehydroepiandrosterone on central and peripheral levels of allopregnanolone and beta-endorphin. Fertil Steril 2005;83(Suppl 1):1161-1168.

43. Guazzo EP, Kirkpatrick PJ, Goodyer IM, Shiers HM, Herbert J. Cortisol, dehydroepiandrosterone (DHEA) and DHEA sulfate in the cerebrospinal fluid of man:relation to blood levels and the effects of age. J Clin Endocrinol Metab 1996;81:3951-3960.

44. Melchior CL, Ritzmann RF. Dehydroepiandrosterone is an anxiolytic in 
mice on the plus maze. Pharmacol Biochem Behav 1994;47:437-441.

45. Galdo M, Gregonis J, Fiore CS, Compagnone NA. Dehydroepiandrosterone biosynthesis, role, and mechanism of action in the developing neural tube. Front Endocrinol (Lausanne) 2012;3:16

46. Reddy DS, Kulkarni SK. Differential anxiolytic effects of neurosteroids in the mirrored chamber behavior test in mice. Brain Res 1997;752:61-71.

47. Mellon SH, Griffin LD. Neurosteroids: biochemistry and clinical significance. Trends Endocrinol Metab 2002;13:35-43.
48. Kartalcı Ş. Testosterone and depression. Curr Approach Psychiatry 2010;2:457-472.

49. Harris DS, Wolkowitz OM, Reus VI. Psychoneuroendocrınology. In: Sadock BJ, Sadock VA, Editors. Kaplan \& Sadock's Comprehensive Textbook of Psychiatry. 8th Edition. Ankara: The Oncu Press (Turkish Edition), 2007, p.130-131.

50. Swaab DF, Bao AM, Lucassen PJ. The stress system in the human brain in depression and neurodegeneration. Ageing Res Rev 2005;4:141-194. 